\title{
Analysis of Variance (ANOVA) Model Approach to Drugs Abuse in Nigeria between the Periods of 2004-2016
}

\author{
Peter $0^{*}$ and Ishaya L \\ Department of Mathematics/Statistics/Computer Science, Federal University of Agriculture, Nigeria
}

Submission: March 01, 2018; Published: June 21, 2018

*Corresponding author: Peter O, Department of Mathematics/Statistics/Computer Science, Federal University of Agriculture, Makurdi, Benue State, Nigeria; Tel: +234(0)8058943244; E-mail: ptrnch@yahoo.co.uk

\begin{abstract}
Drug abuse is becoming increasing problem in Nigeria. A number of recent studies suggest that almost all Nigerian youths are involved in drugs trafficking/abuse particularly alcohol and nicotine. The major concern is that the number of these youths make it an habit, jeopardizing their own health and safety which in turn create difficulties for their families and the public at large. This study examined the significant difference that exist between the four (4) types of narcotic drugs seized and destroyed by NDLEA per kilogram for the period of 2004-2016, and to specifically know the types of drugs that is more trafficked/abuse in Nigeria in order to proffer a lasting solution. The data obtained were analysed using two ways ANOVA for significance differences and multiple comparisons of means using SPSS version 20. The results of the study reveal that the means of these drugs (Cannabis, Cocaine, Heroin and others) differ significantly and based on the findings cannabis (hemp) demonstrate highest followed by others, cocaine and heroin. The trafficking/abuse of cannabis which is locally done in Nigeria keep on increasing almost every year, most especially in year 2015, the year with the highest cases of drugs abuse compare to the rest of the years. Nigeria as a country will continue to face a growing cases and problems related to drugs trafficking/abuse if adequate measures are not put in place to curtail the menace of such illicit drugs. The researcher offers recommendations that adequate awareness program on the negative consequences of drugs that are prohibited, provision of conventional job opportunities, and orientation program for personnel of law enforcement agents should be made on a constant basis.
\end{abstract}

Keywords: Drug trafficking; Cannabis; Heroin; Cocaine; Cirrhosis; Analysis of variance; Drugs abuse; Illicit drugs; Relieve pains; Dangerous drugs ordinance; Volatile organic solvents; Benzodiapines; Amphetamine-type stimulants; Paracetamol; Two way model; T-test statistic; Ordinary least square method; Consumed; Significant difference; P_value; Alpha value

Abbreviations: NDLEA: Nigeria Drug Law Enforcement Agency; ANOVA: Analysis Of Variance; OLS: Ordinary Least Square Method; LSD: Least Significant Difference

\section{Background of the study}

Humanity has been using drugs mainly to relieve pains over the past century. However the use of drug has degenerated into abuses. In our society today, the menaces of drug trafficking and abuse has reached every part of the globe at an alarming rate. Thus there is a growing recognition that drug is one of the major cause of social, psychological, economic and health problems in Nigeria and Africa at large. Despite the physical and mental health implication, drug abuse continues to be the major risk faced by the youth and adolescents today [1]. Drugs have been in existence for ages and it comes in many forms throughout its existence. For instance, advanced in communication facilities contributed to easy access to drugs among the youth. Hence, methodology used in curbing drug abuse needs to be upgraded to cope with the everchanging technology used in drugs peddling. Drug abuse has been one of the most serious social problems in Nigeria.
The word drug originated from Dutch word "drug" Meaning "dry". This is because most of the early drugs were derived from plants products. Drug means different things to different people but to mean same thing, in all works of life, drug is often seen as a chemical substance (combination) given with the intention of preventing or curing illness or otherwise enhance the physical or mental welfare of men and animal. The use has come to age but has degenerated to abuse, addiction and dependency over the years probably due to uncontrolled or unrestricted supply. For the purpose of this study, "Drug" will be looked upon as any psychoactive chemical substance that is use, not authorized by law. They are those hard drugs (substances) that the law prohibits its usage. The oxford advanced learners dictionary defines hard drugs as very harmful substances that cause changes in the mind or body of it users. They may be smoked, applied, inhaled 
or injected into the body. Examples of such hard drugs include cocaine, heroin, codeine, marijuana, amphetamines narcotics etc.

Drug trafficking therefore refers to unlawful trading, possession and distribution of illicit (hard) drug(s).

The trafficking and use of hard drugs have come of age. According to Ikponmwosa [2] who said trafficking in drug dated as far back as the early 40's. It was introduced by demobilized soldiers who fought in India and Burma during the Second World War. Ever since then phenomenon of illicit trafficking in drug has spread like wildfire. A review of literature shows that interest in drug matters and particularly drug policy in Nigeria has a long history, Pela, et al. [3]. Furthermore they said that the origin of drugs predates in Nigeria since 1960 when the country gained her independence.

According to Oloruntoba [4] pointed out that the first Drug Control Law in Nigeria was enacted in 1935 called 'Dangerous Drugs Ordinance'. This Ordinance function is to regulate the importation, exportation, manufacture, sales, and use of such drugs. He added that alcohol had become a major concern in Nigeria with an evidence of massive arrest of person with possession of prohibited drugs notably cannabis in 1960. The need to curtail sale and use was also a major concern. From that period onward, domestic legislation which focused on the control and prohibition of drugs, especially hemp (Cannabis) became entrenched. In addition, in Nigeria cannabis is also known by various names including "pot", "igbo", "wee wee", "marijuana", "ganja" and "Morocco [3]. He further explained that the vigour and sustained efforts to legislate against drugs in contemporary Nigeria was because of the growing notoriety of the country as a transit point or centre for recruitment of drug carriers, and a growing pattern of consumption of these drugs within the country. In 1980s, it became clear that many Nigerians were getting involved in drugs business, both within the country and beyond, while some persons started using it. This give rise to Nigeria Drug Law Enforcement Agency (NDLEA) to wage war against this menace.

Nigerian youth are fully involved in drug trafficking and abuse especially alcohol and marijuana [5]. Effort has been put in place to checkmate this menace by the federal government with the establishment of drug law agency to monitor importation, exportation, circulation and administration of drugs that is capable of causing cirrhosis which a serious disease of the liver, caused especially by excess drinking of alcohol. In Nigeria, the estimated life time consumption of cannabis among the population is 10.8 percent which is capable of destroying the productivity of the nation. This was followed by psychotropic substances like benzodiapines and amphetamine-type stimulants (10.6 percent), heroin (1.6 percent), and cocaine (1.4 percent) in both urban and rural areas NDLEA, 2012). Drugs abuse appears to be common among males with 94.2 percent than females which is 5.8 percent. Hence, the ages of first use is between 10 to 29 years. The percentage use of volatile organic solvents is 0.53 percent, and is widely spread among the street children, in school's youth and women. The uses of multiple drug happens nationwide with 7.88 percent to varying degree [6]. As the result of frequent use of drugs, more Nigerian youths are becoming drug dependants. The danger of this act is so severe that the society suffer for it since some of them are public servant, drivers etc.

Naturally, certain drugs, especially those that are manufactured for healthy living are good on their own and this is because they are needed by the body to function properly. These types of drugs are manufactured to help the body in one way or the other. They are therefore manufactured with good intention. This drugs become a problem when taken too often or in large dose without proper medical guidance. Furthermore, the problems of drug abuse places a significant threat to the social, health, economic fabrics of the families, society, and the entire nations [7]. Today the menace of drug trafficking/abuse has spread and reached every part of the globe, no nation, no state, no tribe, no race or colour is immune to the devastating problems caused by drug trafficking/ abuse. Hence drug trafficking as mostly viewed possess as a major contributing factor to the increase in crime in the border society. Drugs can be classified according to the work they perform in the human body, e.g. stimulants, depressants, and pain killers. In other words, some drugs are legally and socially acceptable, while others are not. There are also prescription drugs which are often prescribed to patients by doctors. However, it can be taken at individual's own wishes or leisure, e.g. aspirin and paracetamol. Some drugs supplies chemicals that the body needs, but cannot make for itself. Others attack harmful microbes that have invaded the body. Nevertheless, others such as narcotic drugs change the speed at which cells and tissues of the body works.

The problem faced by humanity is that people have continually in searched for ways to make life more pleasurable and to ease the burden of day-to-day survival and hence gives way to drug abuse. Drug abuse is a serious problem faced by the world today. It is found in every occupation; from the entry-level employee to the chief executive officer. The productivity of any nation depends largely on the wellbeing of her citizens which mean the measure of productivity of any nation is directly related to the capacity of the work force. Whenever the work forces of any society indulge in drugs trafficking/abuse, productivity will be negatively affected and thereby resulting in decreasing in standard of living. Therefore the rate at which various drugs are been abused and trafficked should be checkmate in order to curtail it from upward spreading. This research aimed at analysing the quantity of narcotic drugs seized by NDLEA in Nigeria from 2004 to 2016 per kilograms in order to check if the trafficked/abused of various quantities of narcotic drugs are the same or not and also to know if the volume of drugs trafficked/abused across the years are equal or not using analysis of variance two way model without interaction. This means that either all the drugs are consumed at the same level or not in order to find a way out because the side effect of these drugs are not the same though shared a common ground. 


\section{Material and Methods}

The data used in this research work is a secondary data source from National Drug Law Enforcement Agency (NDLEA's) annual reports on the quantity of Narcotic Drugs Seized per kilograms from 2004 to 2016 and two way analysis of variance (ANOVA) model is used. ANOVA is a statistical technique that uses tests, based on variance ratios to determine whether or not significant differences exist among the means of several populations or groups of observations under study. It is an extension of t-test statistic used to determine whether or not two means differs to the case where there are three or more means. The Two way analyses of variance involves the design of experiment to study the effect of two factors such as A and B. Often one of the factors is referred to as "treatment" while the other referred to as "block". The experimental material is been arranged into groups (or blocks) each of which constitutes a simple trial or replication of each treatment in such a way that units assigned to each block are homogenous. Each treatment is then allocated at random to one unit within each block and the blocks are also randomized (Table 1).

Table 1: Data layout for a two way ANOVA without replication.

\begin{tabular}{|c|c|c|c|c|c|}
\hline \multicolumn{5}{|c|}{ Factor B } & \multirow[t]{2}{*}{ Total } \\
\hline Factor A & 1 & 2 & $\ldots$ & b & \\
\hline 1 & $Y_{11}$ & $Y_{12}$ & $\ldots$ & $Y_{1 b}$ & $Y_{1}$ \\
\hline 2 & $Y_{21}$ & $Y_{22}$ & $\ldots$ & $Y_{2 b}$ & $Y_{2}$ \\
\hline . & . & . & $\ldots$ & . & . \\
\hline . & . & . & $\ldots$ & . & . \\
\hline . & . & . & $\ldots$ & . & . \\
\hline $\mathrm{a}$ & $Y_{a 1}$ & $Y_{a 2}$ & $\ldots$ & $Y_{a b}$ & $Y_{a}$ \\
\hline Total & $Y_{. j}$ & $Y_{.2}$ & $\ldots$ & $Y_{. b}$ & $Y$ \\
\hline
\end{tabular}

\section{The two-way ANOVA model}

The two way ANOVA has two model which include model with interaction when the observation with block are replicated and the model without interaction when the observations are not replicated. As presented in equation (3.1) and (3.2) receptively. The model without interaction (3.1) will be adopted since the observations are not replicated.

$$
\begin{aligned}
& Y_{i j}=\mu+\alpha_{i}+\beta_{i}+\epsilon_{i j} \\
& Y_{i j}=\mu+\alpha_{i}+\beta_{i}+(\alpha \beta)_{i j}+\epsilon_{i j} \\
& \text { Where, } i=1,2, \ldots, a ; j=1,2, \ldots, b
\end{aligned}
$$

\begin{tabular}{|c|c|c|c|c|}
\hline Source of Variation & Degree of freedom & Sum of Squares & Mean sum of Squares & F-ratio $(\alpha=0.05)$ \\
\hline Treatment (types) & $\mathrm{a}-1$ & $S S_{\text {factor A }}$ & $M S_{\text {factor } A=} \frac{S S_{A}}{a-1}$ & $F_{\text {Ratio A }}$ \\
\hline Block(Years) & b-1 & $S S_{\text {factor B }}$ & $M S_{\text {factor } B=} \frac{S S_{B}}{b-1}$ & $F_{\text {Ratio B }}$ \\
\hline Error & $(a-1)(b-1)$ & SST & $M S_{E}=\frac{S S_{E}}{(a-1)(b-1)}$ & - \\
\hline Total & ab-1 & & $S S_{T}$ & \\
\hline
\end{tabular}

Table 2: The ANOVA table for a two way classification.
$Y_{i j}$ is the observation (response) at the $\mathrm{i}^{\text {th }}$ level of factor $\mathrm{A}$ and $\mathrm{j}^{\text {th }}$ level of factor $\mathrm{B}, \mu=$ the overall mean, $\alpha_{i}=$ effect of $\mathrm{i}^{\text {th }}$ treatment $\beta_{i}=$ effect of $\mathrm{j}^{\text {th }}$ blocks $(\alpha \beta)_{i j}=$ interaction between treatment effect and block effect

$\epsilon_{i j}=$ random error component

\section{Method of estimating parameters}

The total observed variation, often called total sum of squares is decomposed into the observed variations due to factor A, B and the error as follows. Using ordinary least square method (OLS) (Table 2) 


$$
\begin{aligned}
& S S_{T}=\sum_{i j}^{n}\left(Y_{i j}-\bar{Y}_{\ldots .}\right)^{2}=\sum_{i}\left(Y_{i . .}-\bar{Y}_{\ldots .}\right)^{2}+\sum_{j}\left(Y_{. j .}-\bar{Y}_{\ldots .}\right)^{2}+\sum_{i j}\left(Y_{i j}-Y_{i . .}-Y_{. j .}-\bar{Y}\right)^{2} \\
& S S_{\text {Factor A }}=\sum_{i}\left(Y_{i . .}-\bar{Y}_{\ldots}\right)^{2} \\
& S S_{\text {Factor B }}=\sum_{i}\left(Y_{. j .}-\bar{Y} \ldots\right)^{2} \\
& S S_{E \text { Eror }}=\sum_{i j}\left(Y_{i j}-Y_{i . .}-Y_{. j .}-\bar{Y}\right)^{2} \\
& \text { Where, } \\
& \qquad F=\frac{Y_{. . .}^{2}}{a b}
\end{aligned}
$$

$\mathrm{N}=$ Total observation

$$
\begin{gathered}
S S_{T}=\sum_{i j} Y_{i j}^{2}-C F=\text { Total sum of square } \\
S S_{\text {factor } A}=\frac{\sum_{j} Y_{i . .}^{2}}{b}-C F=S S_{A} \rightarrow \text { Sum of square due to factor A } \\
S S_{\text {factor B }}=\frac{\sum_{j} Y^{2}{ }_{j . j}}{a}-C F=S S_{B} \rightarrow \text { Sum of square due to factor B } \\
\mathrm{SS}_{\text {error }}=\sum_{i j} Y_{i j}{ }^{2}-\frac{\sum_{i} Y_{i . . .}^{2}}{\mathrm{~b}}-\frac{\sum_{j . j} Y_{j .}^{2}}{\mathrm{a}}+\mathrm{CF} \\
\mathrm{SS}_{\text {error }}=\mathrm{SS}_{\mathrm{E}}=\mathrm{SS}_{\mathrm{T}}-S S_{A}-S S_{B}
\end{gathered}
$$

The Hypotheses to be tested are as follows: The narcotic drug that were seized is the available one to be consumed. By direct implications, it therefore means the quantity of narcotic drugs (Cannabis, Cocaine, Heroin and others) consumed across various type and across the year (2004 - 2014) under consideration are the same. The specific hypothesis are:

I. $\mathrm{H}_{0}$ : The mean of all the quantity of narcotic drug seized by NDLEA are the same against.

$\mathrm{H}_{1}$ : The mean of all the quantity of narcotic drug seized by NDLEA are not the same.

II. $\mathrm{H}_{0}$ : The mean of all the quantity of narcotic drug seized across the years are the same against

$\mathrm{H}_{1}$ : The mean of all the quantity of narcotic drug seized across

\begin{tabular}{|c|c|c|c|c|}
\hline \multirow[b]{2}{*}{ Treatment } & \multicolumn{4}{|c|}{ 95\% Confidence Interval } \\
\hline & Mean & Std. Error & Lower Bound & Upper Bound \\
\hline Cannabis & 297440.5 & 32193.139 & 232149.787 & 362731.213 \\
\hline Cocaine & 1486.03 & 32193.139 & -63804.679 & 66776.746 \\
\hline Heroin & 102.11 & 32193.139 & -65188.607 & 65392.818 \\
\hline Others & 22324.67 & 32193.139 & -42966.041 & 87615.384 \\
\hline
\end{tabular}
the years are not the same.

\section{Multiple means comparison (Post Hoc)}

Suppose that in conducting an analysis of variance (ANOVA) for the fixed effect model, the null hypothesis ( $\mathrm{HO}$ ) is rejected at a given level of significance, meaning that the effects of treatment (factor) means are not the same, it become necessary to know which of the treatment means are significantly different from other(s). The procedure for making these comparisons is called multiple means comparison tests and this research, adopt the least Table 3: Estimated Marginal Means for the Quantity of Narcotic Drugs Seized. significant difference (LSD). The least significant difference (LSD) method simply compares the observed difference between each pair of averages to the corresponding LSD and if $\left|\bar{Y}_{i}-\bar{Y}_{j}\right|>\mathrm{LSD}$, we reject $\mathrm{H}_{0}$ and conclude that the mean differ significantly.

\section{Test statistic}

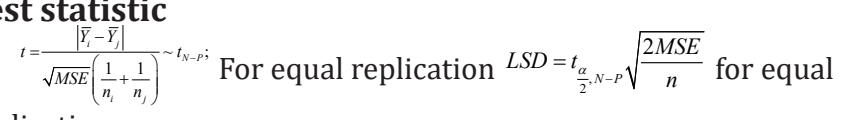
replication

$$
L S D=t_{\frac{\alpha}{2}, N-p} \sqrt{M S E\left(\frac{1}{n i}+\frac{1}{n j}\right)}
$$

The pair of mean and would be declared significantly difference if

$$
\left|\bar{Y}_{i}-\bar{Y}_{j}\right|>t_{\frac{\alpha}{2}, N-P} \sqrt{\frac{2 M S E}{n}}
$$

The quantity $t_{\frac{\alpha}{2}, N-P} \sqrt{\frac{2 M S E}{n}}$ is called the least significant difference (LSD); where $\mathrm{N}$ is the total number of observations, $\mathrm{n}$ is the number of replication, MSE represent mean error from ANOVA table and $\alpha$ is the level of significance. In this work, we make use of LSD with equal number of replications.

\section{Results}

This section present the result of the analysis. Table 3 above present the descriptive statistic for the various categories of drugs and from the table we noticed that cannabis has the highest mean of 297440.50 followed by others with a mean value of 22324.67 , Cocaine with mean value of 1486.03 and lastly Heroin with mean value of 102.11 . Furthermore the $95 \%$ confidence interval of the cannabis shows an upward increases since it does not include zero but cocaine, heroin and others include zero with mean there is upward and downward movement. The implication is that the consumption of cannabis is on the increase alone but that of others, heroin and cocaine fluctuate (Table 4). From Table 5 above which is the ANOVA result for different categories of drugs across the years shows that there is a significant difference between the categories of drugs (Cannabis, Cocaine, Heroin and others) since the p_value of 0.000 is less than the alpha value of 0.05 $(0.00<0.05)$. The implication is that the rate at which Cannabis is consumed is different from that of Cocaine, Heroin and the others but that of years (2004-2016) are not significant since the p_value of 0.385 is greater than the alpha value of 0.05 . The implication is that the consumption of this drugs across the years are the same though we notice a sharp increases in all election years especially 2015 general election which is the year that opposition took over the power recorded the highest number drugs that were seized especially cannabis which is the common of all. This, in a way can be link to some social vices even violent. 


\section{Biostatistics and Biometrics Open Access Journal}

In addition from Table 4, the confident interval of the year 2009 and 2015 contain zero. Since we discovered significant difference between the categories of drugs abused as pointed out by the analysis of variance (ANOVA) Table 5 above, we then move further to what is called post hoc otherwise known as multiple means comparison among the drugs. From Table 6 above, we discovered that there exist significant difference between the cannabis and cocaine, Heroin and others since the p_value of 0.00 is less than the alpha value of $0.05 \quad(0.00<0.05)$. The means comparison between cocaine and heroin are not statistically significant since the p_value of 0.976 is greater than the alpha level $(0.976>0.05)$ and also there is no significant difference between the cocaine and others since the p_value of 0.650 is greater than the alpha level of 0.05 i.e $(0.650>0.05)$.

Table 4: Estimated Marginal Means of the Quantity of Drugs Seized across the years.

\begin{tabular}{|c|c|c|c|c|}
\hline \multicolumn{5}{|c|}{ 95\% Confidence Interval } \\
\hline Years & Mean & Std. Error & Lower Bound & Upper Bound \\
\hline 2004 & 17189.83 & 58037.01 & -100515 & 134894.333 \\
\hline 2005 & 31635.91 & 58037.01 & -86068.6 & 149340.418 \\
\hline 2006 & 51838.21 & 58037.01 & -65866.3 & 169542.716 \\
\hline 2007 & 52869.24 & 58037.01 & -64835.3 & 170573.743 \\
\hline 2008 & 84136.94 & 58037.01 & -33567.6 & 201841.448 \\
\hline 2009 & 123984.6 & 58037.01 & 6280.124 & 241689.136 \\
\hline 2010 & 44530.18 & 58037.01 & -73174.3 & 162234.688 \\
\hline 2011 & 48820.23 & 58037.01 & -68884.3 & 166524.736 \\
\hline 2012 & 58344.09 & 58037.01 & -59360.4 & 176048.596 \\
\hline 2013 & 86246.43 & 58037.01 & -31458.1 & 203950.936 \\
\hline 2014 & 41674.3 & 58037.01 & -76030.2 & 159378.801 \\
\hline 2015 & 225906.1 & 58037.01 & 108201.6 & 343610.646 \\
\hline 2016 & 177222.1 & 58037.01 & 59517.62 & 294926.636 \\
\hline
\end{tabular}

Table 5: ANOVA Result for Tests of Between subjects Effects.

\begin{tabular}{|c|c|c|c|c|c|}
\hline Source & Sum of Squares & Df & Mean Square & F & Sig. \\
\hline Model & $1.34 \mathrm{E} 12$ & 16 & $8.35 \mathrm{E} 10$ & 6.195 & 0 \\
\hline Treatment & $8.21 \mathrm{E} 11$ & 3 & $2.74 \mathrm{E} 11$ & 1.106 & 0.312 \\
\hline Years & $1.79 \mathrm{E} 11$ & 12 & $1.49 \mathrm{E} 10$ & & \\
\hline Error & $4.85 \mathrm{E} 11$ & 36 & $1.35 \mathrm{E} 10$ & & \\
\hline Total & $1.82 \mathrm{E} 12$ & 52 & & \\
\hline
\end{tabular}

a. $\mathrm{R}$ Squared $=.734$ (Adjusted R Squared $=.615)$

Table 6: Multiple Means Comparison (Post Hoc) for the quantity of Narcotic drugs seized.

\begin{tabular}{|c|c|c|c|c|c|c|}
\hline \multicolumn{2}{|c|}{ Treatment } & \multicolumn{3}{c|}{ Mean Difference } & \multicolumn{2}{c|}{ 95\% Confidence Interval } \\
\hline \multirow{2}{*}{$(\mathbf{I})$} & $(\mathbf{J})$ & $(\mathbf{I}-\mathbf{J})$ & Std. Error & Sig. & Lower Bound & Upper Bound \\
\hline \multirow{3}{*}{ Cannabis } & Cocaine & $295954.47^{*}$ & 45527.97 & .000 & 203619.46 & 388289.48 \\
\cline { 2 - 7 } & Heroin & $297338.39^{*}$ & 45527.97 & .000 & 205003.38 & 389673.41 \\
\cline { 2 - 7 } & Others & $275115.83^{*}$ & 45527.97 & .000 & 182780.82 & 367450.84 \\
\hline \multirow{3}{*}{ Cocaine } & Cannabis & $-295950.00^{*}$ & 45527.97 & .000 & 203619.46 & 388289.48 \\
\cline { 2 - 7 } & Heroin & 1383.93 & 45527.97 & .976 & -388289.48 & -203619.46 \\
\cline { 2 - 7 } & Others & -20838.64 & 45527.97 & .650 & -90951.08 & 93718.94 \\
\hline \multirow{3}{*}{ Heroin } & Cannabis & $-297340.00^{*}$ & 45527.97 & .000 & -113173.65 & 71496.37 \\
\cline { 2 - 7 } & Cocaine & -1383.93 & 45527.97 & .976 & -389673.41 & -205003.38 \\
\cline { 2 - 7 } & Others & -22222.57 & 45527.97 & .628 & -93718.94 & 90951.08 \\
\hline
\end{tabular}


Biostatistics and Biometrics Open Access Journal

\begin{tabular}{|c|c|c|c|c|c|c|}
\hline \multirow{3}{*}{ Others } & Cannabis & $-275120.00^{*}$ & 45527.97 & .000 & -114557.56 & 70112.45 \\
\cline { 2 - 7 } & Cocaine & 20838.64 & 45527.97 & .650 & -367450.84 & -182780.82 \\
\cline { 2 - 7 } & Heroin & 22222.57 & 45527.97 & .628 & -71496.37 & 113173.65 \\
\hline
\end{tabular}

Based on observed means.

The error term is Mean Square (Error) $=13473176778.31$.

${ }^{*}$. The mean difference is significant at the .05 level.

\section{Conclusion}

In this research work, an undertaking is been made to examine the significant difference that exist between the four (4) types of narcotic drugs seized and destroyed by NDLEA per kilogram for the period of 2004-2016, and to specifically know the types of drugs that is more trafficked/abuse in Nigeria in order to proffer a lasting solution. From the results obtained it was evidenced that the means of drugs significantly differ and based on the findings, cannabis (hemp) demonstrate highest followed by others, cocaine and heroin. Cannabis and others were the most commonly trafficked/abused drugs and the least was cocaine and heroin in Nigeria. The production, transportation, exportation and possession of cannabis which is locally done in Nigeria keep on increasing almost every year, most especially in year 2015. The year 2015 with the highest cases of drugs seized and destructed compared to other years under study and that is the year Nigeria conducted her last presidential election. Nigeria as a country will continue to face a growing cases and problems related to drugs trafficking/abuse if adequate measures are not put in place to curtail the production, transportation, exportation, possession, distribution and consumptions of such illicit drugs.

\section{References}

1. Hamisu M, Ahmad TO, Lim HL (2014) Adolescent's and Drugs Abuse in Nigeria. Journal of Biology, Agriculture and Healthcare 4: 1.

2. Ikponmwosa A (2015) Drugs Trafficking in Nigeria: It's Effects and How to stop it Once and For All. Information Guide in Nigeria.

3. Pela OA, Ebie JC (1982) Drug abuse in Nigeria: a Review of Epidemiological studies. Bull Narc 34(3-4): 91-99.

4. Oloruntoba F (2006) Drug control Laws in Nigeria. Paper presented at the Teachers Orientation Workshop for Plateau State Teachers in Jos.

5. National Drug Law Enforcement Agency (NDLEA) $(2007,2008,2011$, 2012).

6. http://www.unodc.org/docs/treatment/CoPro/Web_Nigeria.pdf

7. Oshodi OY, Aina OF, Onajole AT (2010) Substance use among secondary school students in an urban setting in Nigeria: prevalence and associated factors. Afr J Psychiatry (Johannesbg) 13(1): 52-57.

\section{Your next submission with Juniper Publishers will reach you the below assets}

- Quality Editorial service

- Swift Peer Review

- Reprints availability

- E-prints Service

- Manuscript Podcast for convenient understanding

- Global attainment for your research

- Manuscript accessibility in different formats

( Pdf, E-pub, Full Text, Audio)

- Unceasing customer service

Track the below URL for one-step submission https://juniperpublishers.com/online-submission.php 